\title{
The Status Quo Research of Exploitation and Utilization of Underground Brine Resources in Yellow River Delta
}

\author{
Yao Teng ${ }^{1, a}$, Haotian Zhu $^{2, b}$ and Juan Feng ${ }^{1, a^{*}}$ \\ ${ }^{1}$ School of Qingdao University, Qingdao 266071, China; \\ 2 School of Qingdao NO.2 High school, Qingdao 266100, China. \\ ay_tfighting@163.com, ${ }^{\mathrm{b}} 1358263016 @ q q . c o m,{ }^{a^{*}}$ qdufengjuan@126.com
}

Keywords: Underground Brine, Complex Exploitation and Utilization, Yellow River Delta.

\begin{abstract}
Shallow-underground brine resources are abundant in Yellow River delta, which are mainly distributed in Wudi-Zhanhua and Dongying brine distribution area. At this stage brine resources have been maturely applied to chemical engineering industries such as salt extracting and soda manufacturing, and have acquired major economic efficiency in industry, which exerts important effects on development of Shandong economy. However, there are some problems existing in exploitation process such as single method and blindfold and out-of-order over-exploitation, therefore, shallow-underground brine cone of depression appeared. On the basis of deficient analysis status quo and drawing lessons from advanced and complex utilization pattern, we directed against the distribution and constitution characteristics of brine resources in these areas and explored model process of complex exploitation and utilization of underground brine in terms of present techniques and experience. We put forward the schemes and suggestions of geologic environment protection in exploitation process and provided new ways of thinking and scientific references for improving intra-regional environment and further exploitation and utilization of underground brine even deep layer brine all over the province.
\end{abstract}

\section{Introduction}

Underground brine, a kind of natural liquid mineral resource, means that the underground water contains several kinds of industrial raw materials and its mineralization is more than $50 \mathrm{~g} / \mathrm{L}$. Brine resources are abundant in Yellow River delta, which are mainly distributed at the zone around the Bohai Sea, the coast of Laizhou Bay and Jiaozhou Bay, among those the most abundant area is the northern coast of Laizhou Bay, that is, the north of Weifang City, the exploitation is also most mature, having famous Haihua Association. At present, the utilization of underground brine in Yellow River delta is still at extensive exploitation stage. The brine resources are mainly used to salt-manufacturing [1], the degrees of deep chemical engineering processing and complex utilization are lower and the environmental geologic problems are serious.

To save brine resources, improve the complex utilization ratio and acquire more prominent economic efficiency, we chose plain areas in Yellow River delta as object of research. On the basis of fully collecting and utilizing the prior geologic outcome data, we understood the distribution range, the status quo of exploitation and utilization and main environmental geologic problems of underground brine resources in the research area. We analyzed the research and put forward the schemes and suggestions about rational exploitation and utilization of underground brine resources and geologic environment protection. At the same time, we provided scientific references for scientific exploitation, utilization and protection of underground brine resources in the research area.

\section{Hydrological and Geological Conditions and Distribution Characteristics in the Study Area}

Geologic Structure. The underground brine in Yellow River delta plain is mainly distributed at Wudi County, Zhanhua County, Dongying Region, Kenli County, Guangrao County and so on, which belong to North China Plate (Grade I ), the segments of North China Depression Area in 
Shandong Province (Grade II) and Jiyang Depression Area (Grade III) in ground structural units. From the north to the south, the major embossments and depressions in mining areas are Chengzikou Embossment, Chezhen Depression, Yihezhuang Embossment, Zhanhua Depression, Chenjiazhuang-Qingtuo Embossment, Dongying Depression, Guangrao Embossment and so on.

With the influence of Xinhua Structural System, the bedrocks in Yellow River delta plain area grow in fragile structure and the activity intensity is huge. The major fractures are Chennan Fracture, Yinan Fracture, Chengdong Fracture, Guangbei Fracture and so on and the major direction of fracture growth are NNE, NE and near EW. The fragile structure shall be latency pattern and it has no influence on cause of formation of brine in mining area [2, 3].

In the area, Quaternary ground layers are intensive and the growth contains Pleistocene series and Holocene series.

Hydrological and Geological Conditions. The study area is hydrological and geological plot with entirely salty void water. It is located in the north of Line Zhanhua-Lijin-Dongying-Guangbei Reservoir and it is the one-dimensional structure area with salt water. The area was formed by several Yellow River floods and depositions and the major lithologies of water-bearing stratums are fine sand and silty sand. Between the water-bearing stratums there are several layers of clay sand, sandy clay or clay. Embedded depth of water level is usually from 2 to 4 meters. The habitat of underground water is bad and the watery characteristic is weak. The water inflow in each well is basically below $500 \mathrm{~m}^{3} / \mathrm{d}$. The fresh water in superficial layer only concentrates around fossil river course. The bottom burial capacity of fresh water is larger and the thickness of water-bearing stratums is huge. Meanwhile, the granule is bulkier and the watery characteristic is greater [4]. The water inflow of each well is usually from $500 \mathrm{~m}^{3} / \mathrm{d}$ to $1,000 \mathrm{~m}^{3} / \mathrm{d}$.

The terrain of Yellow River delta plain is flat and the granule in stratum is tiny. The horizontal runoff of underground water is slow and vertical alternation is the major alternate way. The supplies of underground water are mainly from atmospheric precipitation, infiltration from irrigation with introducing Yellow River water and river lateral infiltration. The excretion pathway is evaporation of phreatic water, sometimes excretion by hand mining also exists in brine exploitation area. The direction of underground water runoff is basically from the west to the east and it runs into the Bohai Sea finally. The water divide is the Yellow River. In the north of the Yellow River the flow direction is NNE and in the south it is SE. But in the brine exploitation area, the runoff of underground water flows to the brine exploitation funnel area.

Brine Distribution Characteristic. In the Yellow River delta plain, the brine is mainly distributed in two areas, that is, Wudi-Zhanhua brine distribution area and Dongying brine distribution area. The brine concentration in the whole Yellow River delta study area is from $5^{\circ} \mathrm{Be}^{\prime}$ to $17.5^{\circ} \mathrm{Be}^{\prime}$ and the total distribution dimension is about $1,403.39 \mathrm{~km}^{2}$.

The brine in Wudi-Zhanhua is distributed among the Zhangweixin River, Tuhai River and Chao River and it extends to be parallel to the coastline in NW-SE [5]. The brine concentration in the area is from $5^{\circ} \mathrm{Be}^{\prime}$ to $13^{\circ} \mathrm{Be}^{\prime}$ and it has obvious zonality in horizontal direction. The concentration appears low-high-low regularity for change from the coastal area to the inland. The variation tendency of brine layer bedplate appears shallow-deep-shallow regularity from the coastal area to the inland and from the west to the east. The thickness of the brine layer is from 8 to 30 meters and around the rear of the West Mountain to the station in Binhai Town, Zhanhua County, the maximum thickness of water-bearing stratums is from 20 to 30 meters. At the same time, around the Chewangcheng Saline in Wudi County and about $2 \mathrm{~km}$ away from the south of East Wind Coast, the minimum thickness of water-bearing stratums is from 5.7 to 9.5 meters while 10 to 20 meters in other places.

The brine in Dongying is distributed at the western coast of the Laizhou Bay between the Yellow River and the Siaoching Ho River and it has obvious zonality in horizontal direction. The brine concentration appears low-high-low regularity for change from the coastal area to the inland. In the vertical direction the brine presents lenticular form and the concentration also has obvious zonality. The thickness of brine layer is from 6.6 to 25.4 meters. The maximum thickness of water-bearing stratums in the south of Guangnan Reservoir and the north of Guangrao Saline is from 20 to 25.4 
meters and the minimum thickness of it around Nanjiao Reservoir to Xin `an Reservoir is from 6.6 to 10 meters, while 10 to 20 meters in other places.

\section{The Exploitation Status Quo and Ways of Complex Exploitation and Utilization of Brine Resources}

The Exploitation Status Quo of Brine. Shandong has great advantages in underground brine resources and it will play an important part in the construction of chemical engineering bases which are coastal and rapid development of regional economy and society. At present, the exploitation and utilization of brine is more mature in Zhanhua County, Guangrao County and Dongying Region and all the brine resources which have been exploited and utilized were buried in the depth that is below 100 meters.

By the incomplete figures, there are 17 mining enterprises producing crude salt and bromide all the area at present, among those Zhanhua County has the most, that is, 10 . The dimension of all the mining area is $47.37 \mathrm{~km}^{2}$ and Guangrao County has the largest dimension of mining area, that is, $25.99 \mathrm{~km}^{2}$. In the area there are 1,162 brine producing wells and the annual exploitation volume of underground brine is about 22.082 million $\mathrm{m}^{3} / \mathrm{a}$. Currently, air blow technique weighs in bromide producing, only several mining enterprises extract magnesium chloride and potassium chloride as well. The annual producing volume of crude salt is about 698 thousand tons and the volume of bromide is about 5.8 thousand tons. It could bring huge economic efficiency and it plays an important part in the development of Shandong economy [6].

The Traditional Mode of Exploitation and Utilization of Brine. The exploitation modes of brine could be divided into brine-crude salt, brine-bromide-crude salt, brine-bromide-crude salt-recovery of bittern-production and so on by the application of brine after exploitation from the underground.

By the water chemistry characteristics of underground brine in study area and comparing three technological processes of exploitation and utilization of brine resources mentioned above, we can see that the brine-crude salt-discharge type only exploits and utilizes sodium chloride of brine and this way has been rejected basically. The brine-bromide-crude salt-discharge type exploits and utilizes sodium chloride and bromide in brine. The brine-bromide-crude salt-recovery of bittern-production- discharge type not only exploits and utilizes sodium chloride and bromide but also utilizes beneficial components in brine sufficiently such as potassium chloride, potassium chloride and calcium sulfate. It can exploit and utilize brine resources in maximum limit, so it is the most rational exploitation and utilization way and could make the most economic efficiency.

The Environmental Geologic Problems Resulted from Exploitation and Utilization of Brine. The exploitation and utilization of brine resources has exerted great effect on economic construction, but in the exploitation and utilization there are some problems such as low complex utilization ratio and excessive exploitation, which could waste resources and result in reduction of brine concentration. And then they could produce environmental geologic problems such as cone of depression of underground brine and ecologic pollution. The problems include reduction of brine concentration, resulting in cone of depression of underground brine, serious waste of resources, low complex utilization ratio of brine resources and so on.

The positive effects of exploitation of brine on geologic environment are slowing down the rate of salinity intrusion and reformative effect on salinization of topsoil. Massive exploitation of brine resources reduces underground water level and evaporation of phreatic water weakens. So the superficial salt accumulation process stops or drops. By the precipitation leaching, the content of easily soluble salt in soil decreases. Then it can promote the reformative effect on salinization of topsoil. Extraction and processing of all kinds of rock salt in natural brine usually adopts ted solidification method, that is, the natural brine is extracted into the beach pools and steamed, shined and concentrated naturally, and then the rock salt reaches saturation and is separated by crystallization. The natural drying of brine needs constructing a great amount of salt-drying pools. Leakage and spilling of salt water must result in the increase of mineralization of underground water around the salt pools. It will exacerbate the soil salination and alkalization, solidification of 
land, degeneration of vegetation and accelerate the depravation of coastal vulnerable terrestrial ecologic environment.

The New Complex Exploitation and Utilization Way of Brine. The exploitation of underground brine resources only includes salt manufacturing, bromine extracting and so on, some parts of those are used to extract magnesium chloride and potassium chloride $[7,8]$. The exploitation and utilization methods include brine-bromide-crude salt, brine-bromide-crude salt-recovery of bittern-salt chemical engineering production and so on. If complex utilization method is adopted and the potential of brine resources is exploded mostly, it can not only increase the volume of salt production but also save the dimension of salt fields. Recently, prawn cultivation and river crab fry reproduction by seawater always produce serious diseases, so people begin to adopt underground brine with no biological pollution to breed crab and shrimp fries or use underground brine and salt water to breed prawns in the water area far away from the sea. The production scale of crude salt and bromide can be determined by ratio 1,000:36 and it can save brine resources.

At present, the complex utilization method of brine in Yellow River delta which has the better effectiveness is following mode (Figure 1). It includes 8 processes, that is, rectification of brine, salt manufacturing by evaporation in vacuum, potassium chloride manufacturing by salt and potassium combined producing, manufacturing potassium mother liquor and extracting iodine, manufacturing iodine mother liquor and extracting bromine, recovery of lithium carbonate, producing soda ash and producing caustic soda. The key of this technical route is the former concentration and rectification of brine and salt manufacturing and complex utilization later. The advantages of it are much more, that is, the technical process is simple, the occupying area is small, the investment of equipments is little, the operating cycle is long, the utilization ratio of quantity of heat and complex utilization and recovery ratio of resources are high and so on. So it is beneficial to manufacture on a large scale. It can not only unitedly produce salt and potassium chloride in high quality but also improve the recovery ratio and concentration of bromine and iodine resources. 


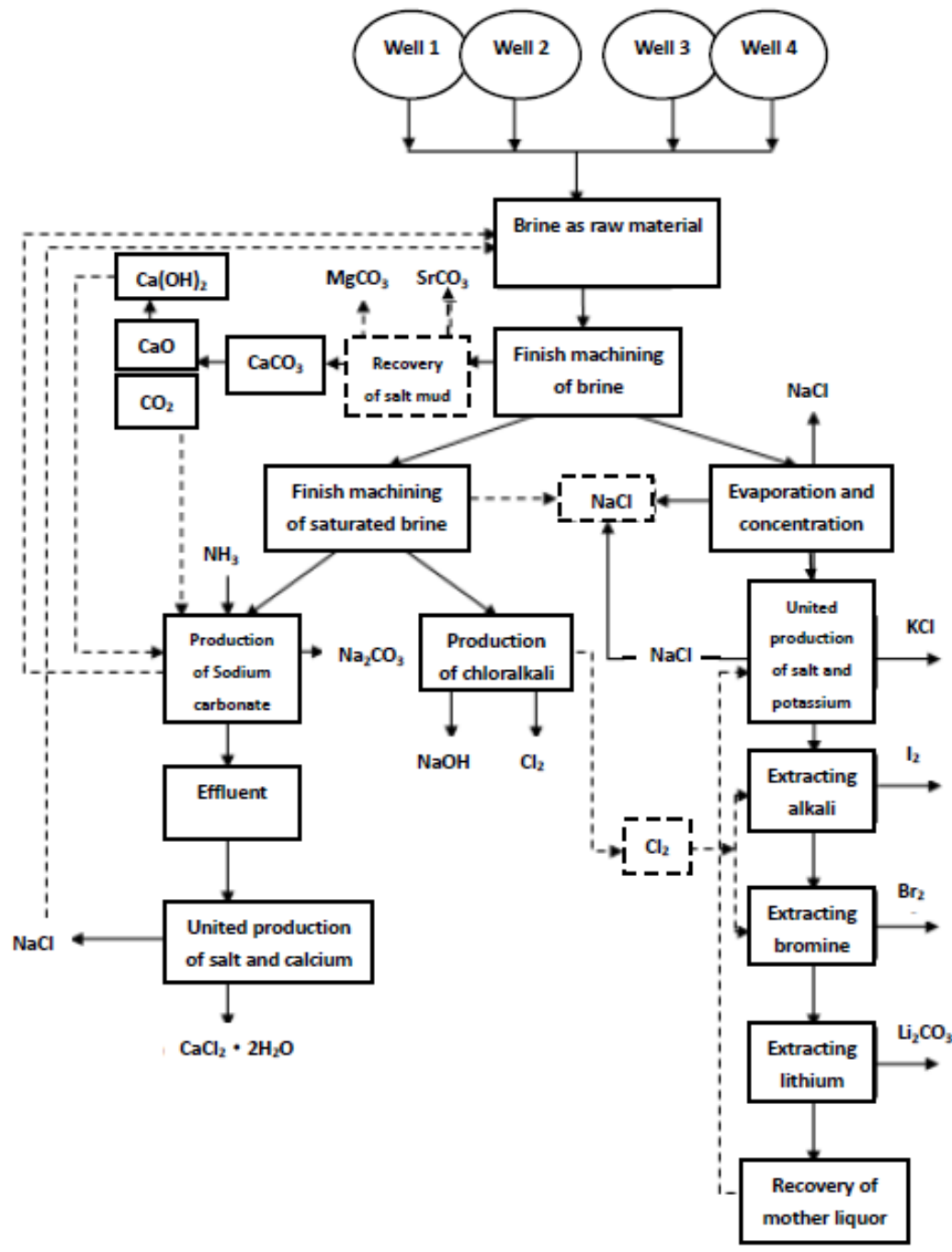

Figure .1 The sketch map of complex utilization mode of underground brine in Yellow River delta

In addition, there still exists other complex utilization methods of brine whose emphasis is producing chemical fertilizer, that is, a kind of new technique of complex utilization of bittern choosing ammonium magnesium phosphate (the nutritive composition is more than 50\%), a kind of three-element slow-acting multiple fertilizer containing magnesium, and potassium sulfate as main products, choosing ammonium chloride or calcium chloride as by-products. Figure 2 shows the process. Ammonium magnesium sulfate has the very little solubility in water, so it is easy to separate magnesium from liquid phase (almost 100\%). 


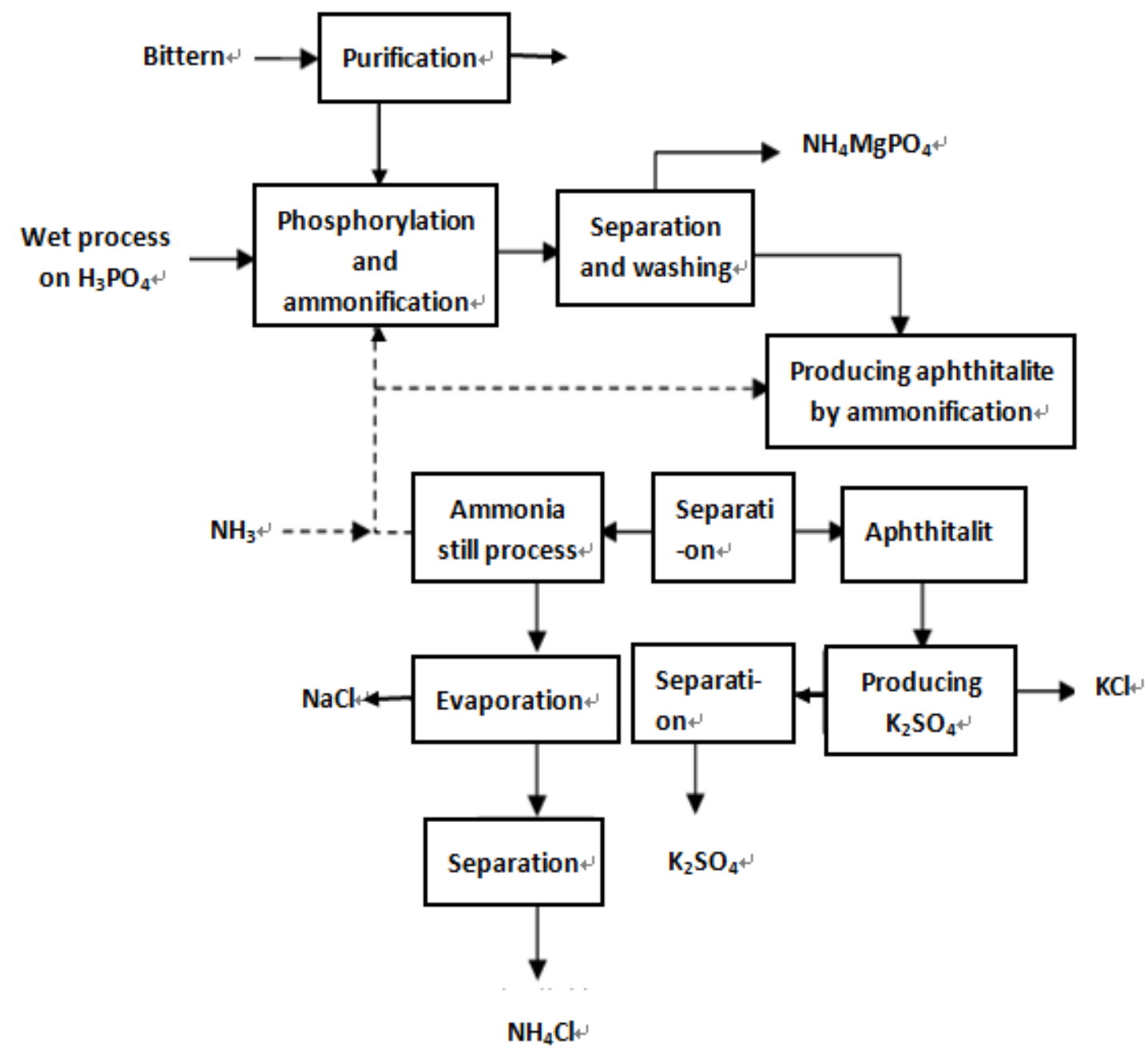

Figure . 2 The complex utilization process of bittern in salt fields whose main product is chemical fertilizer

In complex utilization of salt and bromine, the One Water Five Utilization in Haihua Association in Weifang City is a useful way. After the lifting of brine, it will be used to breed fish, shrimp, crab and shellfish firstly. The concentration of brine constantly increases under the radiation from the sun. When the concentration is from $6^{\circ} \mathrm{Be}^{\prime}$ to $12^{\circ} \mathrm{Be}^{\prime}$, the brine can be used to breed brine shrimp and when it becomes moderate brine, the brine will be sent to the plant for soda ash, the plant for potassium sulfate, the plant for fire extinguisher and so on for technology cooling. After the absorption of heat, the brine will be sent to the plant for bromide and be blown the bromine. It can improve the bromide extraction ratio. The brine which has been blown the bromine should be sent to the saltern for evaporating brine in the sun to make salt. When the concentration reaches $26.5^{\circ} \mathrm{Be}^{\prime}$, the brine would crystallize to make crude salt and produce chemical engineering products such as chloralkali and caustic soda according to finish machining. Finally the brine which has been discharged still could be utilized, because it is the important raw material for extracting production such as potassium sulfate and magnesium chloride. After these 5 procedures, the useful components in the brine have been basically squeezed out. As a result, the whole process is a green industrial chain made up by culturing in brine with low concentration, extracting bromine in brine with moderate concentration, manufacturing salt in saturated brine and producing kali salt, magnesium salt and other related salt chemical engineering products by bittern. This process makes the brine become One Brine More Utilization [9, 10]. It not only helps the enterprise keep costs down and improve economic efficiency, but also the most important thing lies in protecting brine resources, which will make the resources be exploited and utilized rationally and reach the win-win-win with economic, social and ecologic efficiency finally.

In some aquatic products culturing areas, the underground brine with low concentration has replaced the seawater and become the new qualified culturing water source. The temperature of 
underground brine keeps $10 \mathrm{C}$ upper all the year, it can supply the heat and help cultured organisms overcome the winter, which could cut down the costs of production.

\section{Conclusions and Suggestions}

There are abundant underground brine resources in Yellow River delta plain areas and it has great potential in complex utilization. The brine resources in study area are distributed in striped shape along the coastal zone. The exploitation of brine mainly concentrated in Zhanhua County, Dongying Region and Guangrao County and in the area the greatest way of exploitation and utilization of traditional brine resources is brine-bromide-crude salt-recovery of bittern-salt chemical engineering products. However, there still exists some problems in the exploitation and utilization, such as low complex utilization ratio, excessive exploitation and so on, which will waste resources, result in decreasing of brine concentration and produce some environmental geologic problems such as cone of depression of underground brine and ecologic pollution. So we put forward the sustainable exploitation and protection schemes of resources with a clear objective in mind on the issue of exploitation and utilization of brine resources, that is, reinforcing the study of brine in deep layer and perfecting the exploitation and utilization techniques. Combined to the study of supply of underground brine, we defined rational exploitation quantity of brine and maximum acceptable drop depth. We could utilize and protect brine resources in maximum limit and make it serve for construction of social economy in a long time. According to building recycling mode with steps and utilization in several times, perfecting process and paying attention to clean production, we have reached the greatest rational process of complex exploitation and utilization of brine. Adopting the complex utilization way and excavating potential of brine resources most possibly, it can not only increase the output of salt but also save the dimension of salt fields. If we exploit and utilize brine resources complexly and in steps according to the principle of One Brine More Utilization, finish the utilization of waste liquor in salt manufacturing, that is, bittern, and reach the condition in which deciding bromine by salt and existing balance between salt and bromine, we can exploit and utilize underground brine resources rationally and effectively on a further step and energetically develop salt manufacturing, salt chemical engineering and related industries. Furthermore, we can improve the environment in the area and realize the sustainable and rapid development of national economy.

\section{References}

[1] Taiping ZHANG, Yuelin WANG, Jiping SHOU, et al. Suggestions on Development and Utilization of Underground Brine Resources in Northern Changyi City. Land and Resources in Shandong Province. Vol. 25(2009) No. 8, p. 21-24.

[2] Zuguang ZOU, Dongsheng ZHANG, Zhirong TAN. Ground Brine Resource and Its Exploitation in Shandong Province. Geological Survey and Research. Vol. 31(2008) No. 3, p. 214-221.

[3] Xinwen ZHANG, Songtao HU, Caiping HU, et al. Strata Characteristics and Forming Condition of Shallow Underground Brine in Coastal Areas of Zhanhua County in Shandong Province. Land and Resources in Shandong Province. Vol. 25(2009) No. 10, p. 28-31.

[4] Liang YI, Hongjun YU, Xingyong XU, et al. Preliminary Study on Coastal Zone Environments and Functional Zoning in Laizhou Bay. Coastal Engineering. Vol. 29(2010) No. 1, p. 30-39.

[5] Jin YANG, Qinye ZHANG. Current Status and Existing Problems of the Development of Brine Resources in North Coastal Area of Weifang, Shandong Province. Ocean Development and Management. Vol. 26(2009) No. 6, p. 88-91.

[6] C. Riziero Martinetti, Amy E. Childress, Tzahi Y. Cath. High recovery of concentrated RO brines using forward osmosis and membrane distillation. Journal of Membrane Science. Vol. (2009) No. 331, p. 31-39.

[7] Francois Risacher, Hugo Alonso, Carlos Salazar. The origin of brines and salts in Chilean salars: 
a hydrochemical review. Earth-Science Reviews. Vol. (2003) No. 63, p. 249-293.

[8] Xiaodong LI, Hongyun SHAN, Ying ZHOU. Treatment of Acid Underground Brine Water and Choice of Treating Materials. Fisheries Science. Vol. 25(2006) No. 7, p. 360-363.

[9] JI Lv, Chengjun LIU, Ning ZHENG, et al. The Processing Research on the Underground Potassium,Boron and Bromine Bittern of the Sichuan Basin. Express Information of Mining Industry. Vol. 19(2003) No. 10, p. 16-18.

[10] Xiaohui LUO, Fugen ZHOU. Discussion on the Realization of Selective Mining of Rock Salt Deposit through Purification of Underground Brine. China Well and Rock Salt. Vol. 37(2006) No. 6, p. 31-33. 